\title{
Action research in Singapore: where are we now?
}

\author{
Salleh HaironiD
}

Correspondence:

hairon.salleh@nie.edu.sg

Nanyang Technological University

National Institute of Education,

Singapore, Singapore

\begin{abstract}
Since the introduction of Learning Circles (a particular model of action research) by the Ministry of Education (MOE) in 2000, action research has grown to become fairly ubiquitous in Singapore education both school- and system-wide in terms of its terminological usage and practice. However, despite its progressive developments over a period of about 15 years, challenges still abound for teachers who seek to enact action research, which range from teachers' heavy workload to the hierarchical work culture. This paper seeks to elucidate not only the historical developments of action research, but also the challenges that are still faced by those who enact it. The analysis of both the historical development and potential challenges serve to highlight the political, social and cultural nuances influencing the implementation of a system-wide approach to action research in Singapore.
\end{abstract}

\section{Introduction}

The term action research was first introduced to all public schools by the education ministry in the year 2000 with the introduction of a teacher collaborative platform called 'Learning Circles'. It was formed at a time when the education system was undergoing major shifts in education reforms starting in 1997 (Hairon \& Dimmock, 2012). It was wrought out of education policymakers' deep realization that significant changes must take place in the education system and schools in a comprehensive manner so as to perpetuate the state's objective of providing a work force that meets the needs of the future economy. One main strategy was to increase the quality of teachers through self-directed collaborative teacher learning and development using action research (Hairon \& Dimmock, 2012). Action research can thus be an appropriate method or tool in enhancing teacher competency in crafting appropriate school curriculum and instruction to meet twenty-first century teaching and learning outcomes. In their analysis of teacher professional learning in selected countries around the world, Darling-Hammond, Wei, Andree, Richardson and Orphanos (2009) have identified action research as an exemplary model of teacher professional learning for quality instruction.

Notwithstanding the debate whether action research in education can be done by individual teachers (e.g., Cochran-Smith \& Lytle, 2009; Stenhouse, 1975) or teachers in collaboration with others (e.g., Cohen et al., 2013; Elliott, 1998; Groundwater-Smith \& Mockler, 2005; Kemmis \& McTaggart, 1988), action research - as discussed in this paper - is generally defined as a critical reflective process involving inquiry and

(c) The Author(s). 2017 Open Access This article is distributed under the terms of the Creative Commons Attribution 4.0 International License (http://creativecommons.org/licenses/by/4.0/), which permits unrestricted use, distribution, and reproduction in any medium, provided you give appropriate credit to the original author(s) and the source, provide a link to the Creative Commons license, and indicate if changes were made. 
discussion in which practitioners work collaboratively towards solving problems by using research methodologies and principles (Glanz, 2014; McNiff, 2013). A basic cycle of action research would include the plan-act-observe-reflect actions, which would then lead to another cycle of the same set of actions (Fig. 1).

Action research has the potential to help teachers improve teaching through a systematic action-oriented inquiry (Martinovic et al., 2012; Sagor, 2000). The disciplined step-by-step process of inquiry in an action research cycle can potentially produce continuous improvement in teaching practice that improves teachers' knowledge on teaching and learning. This step-by-step process includes establishing the research problem, reading the relevant literature, crafting the research question, setting up of the research design, collecting data, discovering the findings, and sharing the findings to the teaching community. What is also powerful in this process is the affordance action research gives to the development of teacher agency or self-directedness (Zeichner, 2009). When action research is done collectively with teachers sharing like-minded concerns and issues, the benefits extend to include emotional support (Elliott, 1991) and knowledge construction (McGee, 2008).

Action research has thus become more attractive than ever to policymakers, school leaders and school teachers - especially considering the growing demands and complexity that bears upon school teachers and leaders in reforming and innovating curricula to attain a diverse and broadened set of student learning outcomes, which include the teaching of science in schools. The use of action research in science education has long been observed (e.g., Capobianco \& Feldman, 2002, 2006; Feldman, 1996, 1999, 2002). This could be due to a focus on scientific thinking shared by protagonists of action research - especially those with the slant towards positivistic mode of inquiry, and science education. Science teachers would thus be more inclined to participate in action research as they are familiar with scientific thought and thinking. In the Singapore context, the teaching of science, as in any other subjects, needs to be revamped in ways that are consistent with what the education ministry sees as essential to help students acquire relevant twenty-first century learning outcomes. However, the translation of new curricula to classroom contexts cannot be carried out by teachers unreflectively (Tan \& Nashon, 2013), and this is where action research finds its relevance.

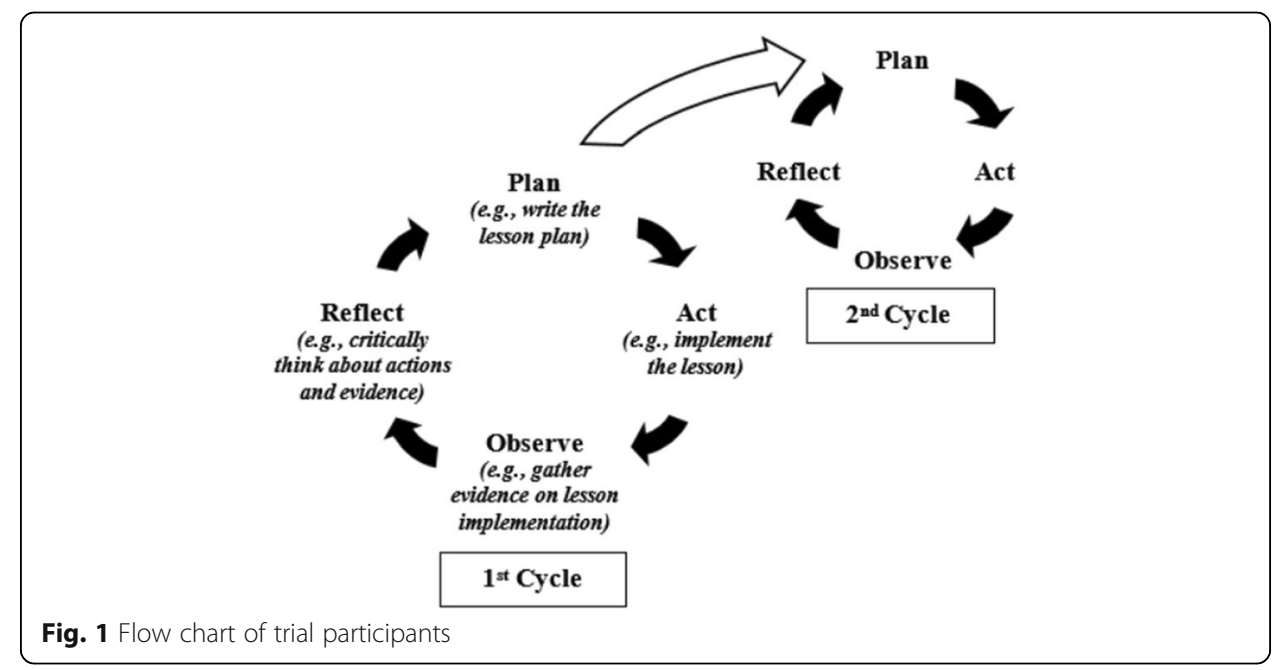


Also, Singapore school teachers and leaders are compelled to invest in school-based curriculum development and innovation in order to provide suitable curricula that develop students in twenty-first century competencies (e.g., creative thinking, critical thinking) yet maintaining its sterling performance in student academic outcomes. To sustain this effort, appropriate professional development provisions need to be given to teachers to enable and empower them to chart their own learning together with their respective school teachers and leaders. Action research is therefore employed by educators to fill in the gap between current realities and desired outcomes in teaching and learning outcomes.

The purpose of this paper is to reflect on the relevance of action research - past, present and future - in the context of teacher professional learning in Singapore. The first section provides the development of action research since its introduction in 2000 by the Ministry of Education (MOE) to school teachers. The second section provides a critical discussion on the potential challenges of implementing action research in Singapore public schools. The arguments raised in this paper is primarily based on relevant literature and my ongoing professional work and interactions with school teachers and leaders in support of their action research endeavours. The concluding section highlights some key perspectives and implications that users and supporters of action research can consider when using and implementing action research.

\section{Historical developments of action research in Singapore}

\section{Learning circles from teachers network}

Action research made its first entry to the Singapore education scene in 2000 with the name 'Learning Circles'. Learning Circles (LCs) was a product of Teachers Network formed in 1998 - a unit within the Training and Development Division of the MOE (Tang, 2000; Tripp, 2004). Teachers Network was formed with the intent to (1) build a fraternity of reflective teachers dedicated to excellent practice through a network of support, professional exchange and learning; and (2) to serve as a catalyst and support for teacher-initiated development through sharing, collaboration and reflection leading to self-mastery, excellent practice and fulfilment. It advocates a bottom-up approach to change, which is encapsulated in its slogan "For Teachers, By Teachers" (MOE, 2005). The major tenets of LCs are voluntary participation, reflection, change and trust. The value of teacher-initiated professional development through sharing, collaboration, reflection and inquiry is embodied in its key platform for teacher learning - namely, LCs.

An LC consists of groups of self-directed teachers engaging in action research to solve problems pertaining to the curriculum that have been collectively identified. LC members utilize about eight two-hour sessions over a four- to twelve-month period. LCs are facilitated by team leaders whose primary role is to provide leadership to discussions and research, identify resource persons, function as critical friends, and assist in the publication and/or presentation of research findings. LC members are involved in an action research cycle of initial reflection, planning, action, observation and critical reflection. Although LCs do not have any epistemological slant, there is a tendency to adopt pre- and post-testing along with a 'technical knowledge interest' posture (Habermas, 1971) - that is, the importance given to control and prediction in research, as opposed to the 'practical knowledge interest' and 'emancipatory knowledge interest'. While the former places importance on interpretation in research, the latter on matters 
on power relations such as domination, oppression and emancipation. At the end, a Group Reflective Journal is written to summarize the action research processes. The contents of this journal could be used for sharing of key findings drawn from action research projects to the teaching fraternity within or beyond the school.

The landmark establishment of Teachers Network and LCs came out of the state's initiative to achieve a learning society - the essence of which is found in the policy initiative slogan, "Thinking School, Learning Nation", or TSLN for short, which was introduced in 1997. The introduction of LCs provided an additional option for teachers on top of just-in-time workshops and in-service courses. The TSLN initiative, which was a watershed period in the history of Singapore education, has three main thematic objectives (Hairon \& Dimmock, 2012). First, to support curricular development and innovation. Second, to encourage school autonomy on curricula and pedagogy. Third, to increase teacher competency. All three developments were designed to give greater scope for both school leaders and teachers to initiate school-based curricular and pedagogical development and innovation. The center piece in the TSLN policy initiative was a systemic curriculum review, leading to a reduction of subject content so as to fulfil broader learning outcomes involving national education, information and communication technology and thinking skills. With regard to school autonomy, emphasis was placed on self-evaluation and external validation using a quality management framework - termed the "School Excellence Model". Schools were also encouraged to establish their own curricular niches with the provision of additional funding for sustained success in those niche areas - a process that gained a number of schools the status of "Autonomous Schools", and the majority of schools "niche" status. With respect to teacher competency, a major revision took place in staff appraisal with the implementation of the Enhanced Performance Management System in 2001. Its key feature was the creation of three career tracks (teaching, leadership, and specialist) along with key competencies and areas of responsibilities for each track, and a detailed framework for performance, promotion and pay.

With the growing emphasis on school-based management and school-based curriculum development and innovation, the need to strengthen teacher competency to support the latter through appropriate professional development becomes understandably salient. It is within this specific context that action research, albeit bearing LCs in name, became increasingly valuable insofar as it is seen as having the potential to promote teacher-initiated learning via collaborative, reflective and inquiry means. Action research can also become a process whereby teachers are encouraged to become selfdirected in learning with other like-minded teachers to improve the curriculum, teaching practice and students learning by putting to test or refine their knowledge on teaching through a systematic and rigorous inquiry (Freeman, 1998; Sagor, 2000).

\section{Action research model from North Zone schools}

Since the introduction of LCs, interest in action research grew in momentum. Another significant development that took place resulting from this interest was the endorsement made by the director of the schools in the North Zone (out of the four geographical zones in Singapore) in the use of action research for all teachers at the individual or group basis. This endeavour resulted in the action research symposium in 2005 which showcased 60 action research projects from the work of 200 teachers from 52 
schools captured in a publication entitled 'Celebrating Learning through Action Research (CLEAR) Symposium'. The symposium aspired to raise the quality of action research in terms of methodological rigour and academic standing. Workshops on research method albeit focusing on more positivistic research paradigm were conducted to train and support teachers in their action research projects involving the submission of action research reports for the symposium (See also Tan et al., 2009). A template was given to teachers to simplify the steps used in action research, albeit favouring quantitative research designs (Soh, 2006a, 2006b). The same pursuit for methodological rigour and academic standing was sought after in CLEAR Symposiums 2006 and 2007, along with the corresponding CLEAR publications (Soh, 2011).

The North Zone Action Research therefore has a marked distinction to that of LCs insofar as it favours the use of quantitative research methods consistent with the positivist paradigm. Nevertheless, both the North Zone Action Research and LCs are two models that teachers in school can use for their action research endeavours. The concern over rigour in action research is a sign of discontentment by a segment of school teachers and leaders over the seeming lack of attention given to research designs in LCs. The progenitors of LCs were more concerned with getting action research processes in place, and gave much more emphasis on teacher agency, reflection, and collaboration but at the expense of emphasis on research designs. The lack of attention given to research designs might also cause teachers, who are less attuned to research, to erroneously believe that rigour in action research, or research in general, can only or primarily be done using quantitative means. In the initial stage of implementing LCs, staff members from Teachers Network first meet with school leaders who are keen to do action research and conduct a talk to teachers in their respective schools before schools make the decision to use LCs. If the decision is forthcoming, staff members from Teachers Network will provide training to LC facilitators and handhold the LC sessions through modelling, feedback and guidance. Subsequently, they will only provide on-site support when required. Over time, this model of support subsided due to resource constraints as more and more schools joined in the LC movement. Conversely, the North Zone model of action research adopted a more centralized approach. The initial years took an opt-out approach. Schools in the North Zone were expected to participate in action research. Consequently, this approach morphed into an opt-in approach. In the latter years after 2007, the symposia gradually ceased. School leaders were to then decide if they want to participate in action research, and if so, the extent (full or partial school-wide) of it. Regardless of their choice, support in the form of training for teachers on relevant knowledge and skills on action research were provided. Currently, the action research promoted by the North Zone remain to favour quantitative research designs, while the one promoted by Teachers Network in the name of LCs remain to be devoid of any preference in terms of research designs. The predilection for the former is primarily the result of teachers' preference for quantity and certainty to determine the efficaciousness of their day-to-day teaching strategies.

At the policy level, interest in action research was motivated by the "Teach Less, Learn More" (TLLM) policy initiative introduced in 2005. The three contextual forces that underpinned TSLN comprising the promotion of curricular development and innovation, school autonomy, and teacher competency took further shape with the TLLM policy initiative. The following key changes were observed (Hairon \& Dimmock, 
2012): focus on both academic achievement and holistic development in student learning; major reviews and revisions of the curriculum for primary and secondary schools and junior colleges; further curricular content reduction; encouragement of schoolbased curricular development; promotion of pedagogical innovations; greater flexibility in the management of curricular content and use of curricular time; provision of greater educational flexibility and choice for students and parents; and refinement of the assessment and streaming framework. Schools that are successful in implementing specialized curriculum focus over a sustained period of time were given autonomous status and extra funding. The MOE made explicit its desire for school-based curriculum initiatives consistent with the slogan of "Bottom-Up Initiative, with Top-Down Support" (Tharman, 2005). Greater recognition was given to the central importance of the teacher in making an impact on classroom learning, as the teacher came to be seen as the ultimate implementer of educational policy. Increases in teacher numbers, teacher quality (for example, revising pay to attract graduates) and adjunct teachers were also legislated. However, the main thrust for measures to raise teacher competency since 1997 rested on teacher professional development, thereby explaining the MOE's investment and commitment to improving teaching quality. Teacher professional development policy has thus been aimed at increasing teacher competency and school autonomy via enabling school-based curricular development and innovation along with the support of school leaders. The spirit of action research that augments teacher's initiative in solving problems, making improvements and experimenting with innovations pertaining to teaching is consistent with the spirit underlying school-based curriculum development. Interest in action research due to the TLLM policy initiative was evidenced from the various publication of teachers' action research projects which include the CLEAR symposia proceedings (MOE, 2005, 2006, 2007), the Research Reports 2007 which put together 29 action research reports, and the North Star which is a journal instituted by MOE targeted at teachers (Soh, 2011). These publications report on action research projects by teachers who had used action research models espoused by LCs or North Zone Action Research.

\section{Lesson study as an alternative to action research}

Besides action research, the move towards school-based curriculum development and innovation underscored by the TLLM policy initiative had also advocated the use of lesson study starting in 2005 (Lim et al., 2011). Lesson study, which has its origins in Japan, is a process used by teachers to collaboratively learn from one another to design, implement and improve lesson plans and delivery of lesson instruction through group discussion and peer lesson observations. Faculty members at the National Institute of Education (NIE) had a significant influence in promoting lesson study through the provision of training, workshops and conferences - specifically, the World Association of Lesson Studies. It has been reported that between 2005 and 2010, 170 out of 354 (48\%) schools in Singapore had received some exposure of lesson study through introductory workshops (Lim et al., 2011). Interest in lesson study as a tool for inquiry in teachers' professional learning is understandable taking into consideration the push for more rigour in the action research process in terms of adopting a more positivistic-quantitative and academic slant.

Pushing action research towards this direction had unintendedly marginalized teachers who may not be in favour of this method of inquiry in their professional learning, in 
addition to the needed time to acquire and practice quantitative research skills. The situation gets worse when teachers who may not be in favour of adopting a positivisticquantitative and academic slant are somewhat forced to adopt such a position. Although lesson study is considered as a form of inquiry into teaching practice, proponents of lesson study generally may not expect teachers to be setting up a research problem, research conceptual/theoretical frame, research question, research design, and systematic data collection and analysis to answer the research question. However, this does not mean that teachers cannot integrate the action research steps in the lesson study cycle as long as it does not contravene the conventional principles of lesson study such as collaboration, planning for lessons, peer observation, and focus on student learning.

\section{Growth in teacher leaders}

Another policy initiative that has helped to enhance the utility of action research in the Singapore setting is the growing importance and recognition given to teacher leaders. This has roots in the MOE's decision to introduce a three-career track structure in 2001 (Teacher, Leadership and Specialist Tracks) in the teaching profession along with the attendant job scope and responsibilities, and competencies, which correspond to the ascending substantive grade within each track. Teachers thus have the choice to opt for the Leadership Track which leads to positions such as middle (e.g., Subject Heads, Heads of Department) and senior (Vice-Principal, Principal) leaders, or the Specialist Track which leads to positions in the MOE HQ specializing in a myriad of specializations such as curriculum, counselling, special needs, policy, and research. They also have the option of remaining in the Teaching Track, which leads to positions such as Senior Teachers (STs) and Lead Teachers (LTs) who reside in schools, and Master Teachers (MTs) and Principal Master Teachers (PMTs) who reside in the respective divisions at the MOE HQ.

The primary role of STs is to mentor beginning teachers and teachers with teaching issues, and support the school's overall effort at developing teachers especially in their specialized teaching subjects. The primary role of LTs includes that of STs in addition to leading and supporting teacher development within a school cluster (or district). Both STs and LTs usually coordinate their work with the School Staff Developers in their respective schools. The MT's role focuses on developing the curriculum in specific subject areas (e.g., Math, Science), developing the competency of teachers teaching in their specific subject areas, and mentoring STs and LTs. The PMTs' role include the MT's role plus mentoring and grooming STs, LTs and MTs to grow as teacher leaders. These leadership positions within the Teaching Track are formal in nature. As teacher leaders, all STs, LTs, MTs and PMTs would be conversant in action research insofar as they are competent in the knowledge and practice of action research, and helping fellow teachers grow in their knowledge and practice of action research so as to eventually deepen teachers' knowledge on teaching in their respective subject areas.

\section{Action research in professional learning communities}

Another policy initiative that has helped to formalize and solidify action research in the Singapore teaching profession is the Professional Learning Community (PLC) policy initiative introduced in 2009. The PLC policy initiative matches perfectly with the TLLM policy initiative as it provides the school-level platform to operationalize the ideals of school-based curriculum development and innovation movement. The policy 
initiative essentially aims to encourage all schools to nurture and support groups of teachers in their Professional Learning Teams to initiate collaborative learning so as to improve teaching practice in the hope of meeting diverse twenty-first century student learning outcomes (Hairon \& Dimmock, 2012). The major aims of PLC are to enable students' learning; build a culture of collaboration; and focus on student outcomes. It also employs '4 Critical Questions' in the PLC discussion sessions - What is it we expect students to learn? How will we know when they have learned? How will we respond when they don't learn? How will we respond when they already know it? At a system level, Professional Learning Teams have the choice of adopting three types of collaborative methods/tools coined by the MOE: LCs, Action Research (which favours the positivist slant historically proposed by the North Zone schools) and Lesson Study - all of which rely on inquiry as the mode of professional learning to improve professional practice. As of now, while LCs still keep its action research cycle of reflection, plan, act, observe, and critical reflection, Action Research still keeps its preference for an action research cycle using positivistic research slant. Lesson Study is the exception where the research part of inquiry is not required.

Generally speaking, schools and teachers are to adopt a 'cyclical process of continuous improvement' which includes the following: use of data to identify student needs; study and analysis of teachers' own and peer research; engagement in rigorous reflection; use of research and professional wisdom to make good choices; collaborative experiment with new teaching practices; monitoring and assessment of implementation; and communication of information to other stakeholders. Professional Learning Teams are directed and supported by a Coalition Team comprising the senior leaders (e.g., principal and/vice-principal) and a few middle leaders (e.g., Head of Department), whose role is to provide direction in tandem with the school's vision, mission and values, and the appropriate structures, processes and resources to support PLCs.

The introduction of the PLC policy initiative also marked the demise of Teachers Network to make way for the establishment of the Academy of Singapore Teachers (AST) set up in 2010 with the aim of building a teaching fraternity that pursues teacher-led professional development and learning in support of school and students' outcomes. The PLC initiative attests to the importance of action research insofar as it now becomes not only a ubiquitous object of utility for all teachers to use in their PLC, but also a means by which teachers are compelled to take initiative in what they want to solve and innovate in their teaching practice. The developments of action research from Teachers Network to AST mean that it has successfully become institutionalized whether it is in its perceived strong form (i.e., Action Research promoted in the North Zone Schools) or its perceived weak form (i.e., LCs promoted by Teachers Network). The institutionalizing of action research in PLCs state-wide means that action research has grown in currency and ubiquity.

\section{Lingering challenges}

Although action research has taken roots in the Singapore education, its system-wide implementation is not without challenges.

\section{Prioritizing action research}

The first challenge that teachers may face in committing to action research is prioritizing action research in the midst of other non-teaching responsibilities and demands. 
Schools are busy places and time has always been a constraint to teachers (Hairon, 2003, 2006; Kuntz et al., 2013; Liew, 2005). In a small island Asian nation state such as Singapore, societal values such as hard work and productivity, thrift, long-term orientation and pragmatism flourish. Furthermore, the lack of natural resources due to the small size of the country puts a premium on human resources. The productivity of teachers therefore cannot be compromised and ought to be optimized. The laundry list of things that teachers have to do on a teaching day can be inexhaustible. Besides attending to teaching responsibilities (e.g., classroom teaching, marking of students' written work and test/examination scripts, lesson planning, lesson preparation, marking, setting of test and examination paper, counselling of students, communication with parents, after school remediation classes, etc), teachers in Singapore are also heavily involved in non-teaching responsibilities such as attending to regular department meetings, weekly or fortnightly staff meetings, special committee meetings (e.g., publication, staff welfare, etc), recess or gate duties, co-curricular activities (e.g., club master, teacher in-charge of a sport).

In addition to this, the administrative work needed to support both teaching and non-teaching responsibilities adds a further burden to teachers. Within such a context, it is perfectly understandable for teachers in Singapore to find difficulty in prioritizing professional development. Based on my interactions with teachers, when they are asked the question, "If your school leader announces that he or she will release 1-hour of curriculum time every week to teachers, what will you do during that period of time?" the consistent answer across the majority of teachers would be, "Mark my students' written work." The lack of priority given to professional development is further exacerbated when the value for productivity (quantity of work) and performance (quality of work outcomes) outstrip the value for professional development. In such a context, the $100 \mathrm{~h}$ entitlement given to teachers for professional development would be insufficient to convince teachers to prioritize professional learning. The realities of school life essentially militate how teachers prioritize the deluge of work that needs to be attended to in the current instance over professional development activities, such as engagement in action research, which will most likely bear fruit some time later. Even though the MOE has institutionalized weekly 1-h curriculum time for all schools to allow teachers to engage in professional learning community endeavours, teachers may see this as another add on to their teaching responsibilities. Depending on the way school leaders communicate and implement this directive from the MOE, teachers may even perceive this as a compulsion as opposed to the ideal of self-directed professional learning.

\section{Ambiguities in the action research concept}

The second challenge that has potential to impede the enactment of action research is the ambiguities inherent in the concept. Although action research is a term commonly used by teachers and schools, a deep understanding of the concept may still be lacking. This becomes understandable when one considers the controversies and confusion about the nature and distinctiveness of the approach used in action research (e.g., Robinson, 1993). There are, nonetheless, a few possible permutations in the way teachers can understand what action research is about. Firstly, the distinction between action research and research. What are key features of action research that distinguish 
itself to the conventional idea of research? Although teachers may generally find this question irrelevant insofar as they just have to get the job of doing action research done, without a full understanding of the term, they might be easily setting themselves up to do something that others cannot validate and affirm. For example, while conventional academic research prioritizes the contribution of new knowledge in the field of study being investigated in order to be considered valid, action research may not. Action researchers prioritize improvements in professional practice (Sagor, 2000) that is informed by theory. Nevertheless, this does not mean that action researchers cannot contribute to new knowledge to existing body of knowledge. Relating to this distinction, teachers may perceive conventional academic research as being superior to action research judging by the kinds of research that are being largely done by teachers in schools and professors in universities. This mindset can be damaging as it could lead to the belief that action research projects done by teacher practitioners is less valid and reliable in contrast to university researchers, which further puts to question the meaningfulness and value of engaging in action research. This perhaps explains why the approach of action research in the North Zone schools in the past gave priority to quantitative research designs as there is a tendency to assume - at least in the Singapore research context - that quantitative is superior to qualitative research method.

A further confusion in understanding action research is existence of other terms on teacher inquiry and the way they are being introduced and used. For example, when LCs were introduced to Singapore teachers, the term action research was not emphasized and not explicitly referred to. The intention of the progenitors of LCs is not to frighten teachers in the use of action research. Rather, the masking of the term by replacing the term 'action research' to 'Learning Circle' was to encourage take-up rate by teachers to reflect on their teaching practice and collaboratively improve their teaching practice. However, when the PLC policy initiative was established, teachers can choose Learning Circle, Action Research or Lesson Study as a tool for professional learning. Teachers may perceive Learning Circle as a lower or poorer form of professional learning tool than action research, while Action Research as a higher or stronger form of professional learning tool by virtue of its reliance on quantitative and statistical devices. This artificial distinction between LCs Learning Circle and Action Research is now set in stone.

The pace of change can also further obscure the clarity in understanding the existing terms introduced to teachers. Before teachers could fully operationalize a new policy initiative in order to understand and appreciate it, they need to grapple with another new policy initiative. When LCs were first introduced in 2000, some teachers took it up immediately but needed two to three iterations in terms of implementing it to fully grasp the concept over a period of two to three years (Hairon \& Dimmock, 2012). If teachers are in the North Zone, they will have to make sense of the differences between LCs and action research. For teachers to fully understand via implementing the model of action research promoted by the North Zone, they would take much longer time due to its higher aspiration towards a more academic research. At the same time, these teachers have to also think through how LCs, action research and lesson study possibly overlap with one another. Their school senior and middle leaders likewise have to grapple with these 
differences in order to communicate the direction and strategies that they need to make in view of these professional development platforms or tools. Clarity among school organizational members can potentially therefore become muddled.

With this potential lack of clarity coupled with the fact that the task of doing research can generally be daunting, lesson study looks set to become an increasingly more viable and popular option for teachers, especially when one considers the 'extraneous' research tasks (e.g., reading of literature, instrumentation, data collection and analysis, publication, etc) at the expense of daily teaching and non-teaching responsibilities that need immediate attention. This reality has been familiarly termed as 'presentism' (e.g., Apple, 1989; Hargreaves, 2010). As teachers are essentially preoccupied with actions pertaining to teaching, they understandably cannot have the luxury of time to do research and become expert in research. This is why action research has been criticized as a 'contradictions of terms' (Hammersley, 2004) - that is, one cannot be an expert teacher and researcher at the same time.

\section{Wide range of knowledge and skills in action research}

The third challenge, which is borne out of the 'contradiction of terms', is the acquisition of the wide range of knowledge and skills required when conducting research. Hammersley (2004) is right to suggest that teachers have difficulties in acquiring wideranging knowledge and skills in action research in the midst of their practical day-today teaching. Notwithstanding the realities of a teacher's day-to-day life, a complete action research cycle could require the following tasks tabulated below (Table 1):

The intention of specifying the above tasks is not to discourage teachers from embarking on action research endeavours, rather to form a realistic expectation on what are required and the specific competencies that teachers need to acquire when embarking on action research endeavours. The challenge therefore is not only time required in developing the specific competencies, but also the people to teach and model these specific competencies.

\section{Development of knowledge and skills in action research}

In extension to Hammersley's (2004) issue relating to the impracticality of being equally good at both research and teaching, the fourth challenge is the development of knowledge, skill and disposition in action research to secure the implementation of action research across the education system. In this regard, three crucial questions to ask are: (1) When do teachers develop the knowledge and skills in action research? (2) How best do teachers develop the knowledge and skills in action research? (3) Who can effectively develop teachers in the knowledge and skills of action research? For the first question, the earlier teachers can be familiar with the practice of action research the better it is. However, the author speculates that teachers may not be substantially exposed to action research in the initial teacher preparation programme as subject content and teaching methodologies and strategies are given priority. Their only exposure may be at schools. For the second question, the author postulates that teachers learn best when they are doing action research in actual practice with real classrooms, students and colleagues. Hence, schools seem to be the best place to be to develop action research knowledge and skills. However, teachers may be so bogged down by teaching and non-teaching responsibilities that they would either not want to participate in 
Table 1 Step and actions in an action research cycle

\begin{tabular}{|c|c|}
\hline Steps & Actions \\
\hline \multirow[t]{3}{*}{ 1. Establish the research problem. } & Reflect on the current situation. \\
\hline & Make observations on selected events. \\
\hline & Narrow down the problem. \\
\hline \multirow[t]{3}{*}{ 2. Be informed by the literature. } & Search relevant literature pertaining to the problem. \\
\hline & Read relevant literature pertaining to the problem. \\
\hline & Glean key ideas and arguments that 'inform' the problem. \\
\hline 3. Set up the purpose of the study. & Establish the purpose of the action research. \\
\hline 4. Craft the research question. & Consider the question/s to be answered. \\
\hline \multirow[t]{9}{*}{ 5. Frame the design of the study. } & Decide on the research design or approach (e.g., survey, case). \\
\hline & $\begin{array}{l}\text { Decide what data to collect, who to collect, when to collect, } \\
\text { and how to collect. }\end{array}$ \\
\hline & Consider how to collect the data in an ethical manner. \\
\hline & Construct the instrument (e.g., questionnaire, interview guide). \\
\hline & Decide on the intervention (e.g., teaching strategy). \\
\hline & Prepare the intervention materials (e.g., lesson plan, teaching aids). \\
\hline & Deliver the intervention. \\
\hline & Collect the data. \\
\hline & Analyze the data. \\
\hline \multirow[t]{2}{*}{ 6. Organize the findings. } & Decide on how the findings will be analysed. \\
\hline & Decide on how the findings will be presented. \\
\hline 7. Summarize the conclusion of the study. & Specify the answer/s to the research question. \\
\hline 8. Explore the implications of the study. & $\begin{array}{l}\text { Consider the implications and actions to be taken based on the } \\
\text { results of the findings, including the next action research cycle. }\end{array}$ \\
\hline \multirow[t]{2}{*}{ 9. Write the report of the study. } & Succinctly write the key components of the action research project. \\
\hline & Ensure that a consistent referencing style is adopted. \\
\hline \multirow[t]{3}{*}{ 10. Share the study findings. } & Decide who to share the key findings and implications of the study. \\
\hline & Decide how to share the key findings and implication of the study. \\
\hline & Suggestion for further investigations. \\
\hline
\end{tabular}

action research or participate in action research in a half-hearted manner so much so that their development is compromised. For the third question, the author posits that STs, LTs and PLC Team Leaders seem to be the appropriate persons to develop teachers' knowledge and skills in action research. They also may be the most ideal persons to role model action research to teachers in schools. However, this model assumes that STs, LTs and PLC Team Leaders are already competent in action research. It also assumes that they do have the time to not only teach, but also model action research to teachers in their respective schools. The reality may not however be so simple and straightforward. First, the knowledge and skills of action research that STs, LTs and PLC Team Leaders have may be uneven across the system. Second, they may hold imperfect knowledge and skills on action research.

\section{Hierarchical work culture}

The fifth challenge that may impede the system-wide implementation of action research is the hierarchical work culture in the centralized education system (Hairon, 
2006; Hairon \& Dimmock, 2012). The attraction of action research is in its potential to encourage teachers to be self-directed in their endeavour to improve their teaching practice when they identify the problem on teaching and learning to explore and test teaching strategies, and along the way to sharpen their professional knowledge. Through this process, teachers become 'extended professionals' (Stenhouse, 1975) who are committed to the -

systematic questioning of one's own teaching as a basis for development; the commitment to and the skills to study one's own teaching; the concern to question and to test theory in practice by the use of those skills. (p. 144).

The ideal of empowerment for self-directed learning embedded in the assertion made above seems, however, to be put into question in Asian education system with high power-distance cultures such as Singapore (Hofstede, 2001). When LCs were first introduced in 2000, its progenitors emphasized the importance of 'voluntary participation'. This explains the initial practice of presenting LCs to schools and leaving schools to decide if they wish to be on board LCs. However, over time when more and more school leaders showed interest in LCs coupled with the lack of manpower to support LCs in its original intent - that is, promoting the spirit of 'voluntary participation' with handholding support, the ideal on 'voluntary participation' waned. With the demise of Teachers Network to make way for the establishment of AST and the PLC policy initiative, LCs along with Action Research become institutionalized professional development tools to be used in PLC settings. This, however, does not mean absolute coercion on teachers to participate in action research. Depending on how school leaders manage the implementation of action research, teachers are still given the choice to choose the topics, research question, strategies and research design, and if they wish to choose Learning Circle, Action Research or Lesson Study.

In a nutshell, the dilemma is in fulfilling the spirit of 'voluntary participation' in action research. On the one hand, the MOE is keen to encourage self-directed collaborative professional learning. On the other hand, teachers may not be so keen to voluntarily take the lead in action research as a form of professional development due to busy work schedule; lack of time to developing research skills; and dependency culture on top-down guidance and implementation. One eventual outcome may be one where teachers embark on action research because it is part of organizational requirement or expectation, but autonomy and agency are given to teachers in terms of choice on teaching pedagogies, and research topics, questions and design. At the end of the day, pragmatism rules over perfectionism (i.e., voluntary participation) in fulfilling the principles and performance of action research. This mirrors what has been considered as successful governance in Singapore, and likewise in education public service, where much depends on a careful balance between coercion and consent (Worthington, 2003). While teachers' engagement in action research can be decided by school leaders and policymakers (a form of coercion), they are however free to choose the direction and scope of their action research projects to benefit their students (a form of consent).

There is a clear need to go beyond debating over the idea of teacher agency or lack of it (Borg, 2010; Groundwater-Smith \& Mockler, 2005; Noffke, 1997), to 
inter-agency whereby teachers, school leaders and policymakers negotiate action research agendas in an inter-subjective manner. Although action research in the Singapore context may not support explicitly the goal in transforming the education system and society at large couched in the term 'critical action research' proposed by Carr and Kemmis (1986), it is not incompatible to the ideals of intersubjective democratic participation. Neither is the approach in action research used in Singapore incompatible with attaining transforming the education system and society. The very objective of teachers' transforming pedagogies would inevitably have positive impact on transforming the education system and society. The need to modify or remodel action research approaches to fit local contexts has been increasingly recognized (Ellis, 2014; Somekh \& Zeichner, 2009). Nevertheless, some may argue that the remodelling of action research could go the other way of 'becoming anything and everything' (Cochran-Smith \& Lytle, 1999).

\section{Singapore pragmatic societal value}

The sixth challenge is to do with the pragmatic societal value that Singaporeans and Singapore teachers hold dear to. When engaging in action research, teachers essentially are motivated by a commitment to the idea of 'rationality and practical results' (Mauzy \& Milne, 2002, p. 52). They would basically have to calculate the benefits and costs of participating in action research. The costs would involve the opportunity to do lesson planning, lesson preparation, marking and other nonteaching tasks, in addition to securing work-life harmony. Furthermore, in school contexts where resources are limited by virtue of the high productivity that are expected of them in terms of quantity and quality of work, there is indeed the need to thrive towards using minimum input to obtain maximum output (Hairon, 2006). The desired output for teachers would be with student learning outcomes which include academic and non-academic outcomes. However, premium is given to the former due to the government's adoption of an exam-based meritocracy where the nation's wealth is distributed according to merit, which is measured and determined by examination.

It is therefore understandable for teachers to carefully consider if investing in action research will take away time and energy at work that impact student achievement. The main problem is thus to do with linking action research actions to that of student learning academic and non-academic outcomes. In the current PLC set up, it is common for teachers to produce a report resulting from their action research journey. This has been the legacy of LCs during its Teachers Network days, and has been transplanted and institutionalized in the PLC policy initiative. Hence, teachers in their PLC teams are expected to submit a write up summarizing their learning journey using LCs, Action Research or Lesson Study. Notwithstanding the benefit of teachers' articulating their knowledge in a written formal way, the unintended consequence is that teachers may view action research as project-based rather than process-based. When they meet during the weekly PLC discussion meetings, the end product is to submit a report to school leaders, and in some schools to submit a report followed by a sharing session in an in-house symposium setting. This might lead to teachers feeling a disconnection between action research and their day-to-day classroom teaching experiences. An extreme illustration is when teachers come together to commit to an action research 
project that lasts only for a month or two in order to primarily satisfy the requirement by the school to submit a report and do a presentation to their teachers about their key findings.

\section{Teacher mindset towards action research}

The seventh and last challenge has to do with the mindset of teachers towards action research. Although there is no nation-wide study to investigate and report the current status of action research implementation in Singapore, the potential challenges that have been raised thus far may not portend well in terms of the sustainable development of a positive mindset towards action research. Teachers themselves must have positive experiences in action research before they want to engage in it. Guskey (2002) is correct to propose that professional development provisions need to change teachers' classroom practices and student learning in order to change teachers' beliefs and attitudes towards professional development.

What attracts teachers to professional development, therefore, is their belief that it will expand their knowledge and skills, contribute to their growth, and enhance their effectiveness with students ... What they hope to gain through professional development are specific, concrete, and practical ideas that directly relate to the day-to-day operation of their classroom (Guskey, 2002, p. 382).

The mindset that action research is a project rather than a process can therefore weaken teachers' belief on action research. The mindset that action research is another add-on to teachers' workload rather than an integral part of the professional practice and identity of a teacher can likewise weaken teachers' belief on action research. A negative teacher belief on action research would only discourage teachers from engaging in action research, or to engage action research to satisfy outward appearances only.

\section{Conclusion}

The task of sustaining system-wide action research in the Singapore education seems rather daunting taking into consideration the slew of potential challenges that have been raised above. However, the fine-grain analysis of the challenges does reveal possible solutions to not only mitigate the problems, but also sustain the system-wide action research implementation. The first task is getting action research embedded in the discourse of the teaching profession. For the Singapore case, this is already done, especially with the two models of action research and its attendant disciplined steps and processes at their disposal. Action research is now one of the professional development tools or platforms that teachers can use in their PLC activities. Hence, the first part of Worthington's (2003) equation on 'coercion' is in place. The second part of the equation on 'consent', however, needs more work. Also, simply institutionalizing action research is not sufficient without leadership direction and support. The leadership direction and support on action research would need to be done systemically - that is, at every level of the system. For the Singapore case, this would include AST, Cluster Superintendents, school senior, middle and teacher leaders. They are the ones who have to continue to communicate to teachers the value of action research. 
The second task is on building capacity of teachers to conduct action research. Although action research is a tool for teacher professional development, there is need to build teachers' capacity and competency to effectively participate in action research. In the Singapore case, both the MOE and school senior, middle and teacher leaders need to consider ways to provide continual professional development provisions to develop the knowledge, skills and disposition on action research of teachers. However, such provisions need to be done regularly and sustained over time, with depth and are embedded in teachers' day-to-day teaching life (Desimone, 2011; Hairon, 2008). Furthermore, the role of teacher leaders is highly significant in terms of providing the time to teach, demonstrate and role-model action research to teachers in contrast to the middle and senior leaders. If the professional development provision takes place outside school (e.g., MOE, NIE School Cluster) the learning should best be done with a practical component which requires teachers to implement it in practice. School clusters can also provide the provision of professional development in action research with the same caveats. Whichever professional development provision is employed, demonstrating or role-modelling how action research is done can be emphasized as this is often overlooked in teacher professional development. Modeling of action research practices is a quick, if not the quickest way, of helping teachers grasp the concept and acquire the skills of action research.

The third and final task is to strengthen the links between action research and student learning outcomes. In this regard, the contributions from university academic researchers - which are currently not prevalent, can become significantly helpful. Thus far, no local research has investigated the impact of action research activities on teacher and student outcomes. This is reflective of the lack of attention and investment to research investigating impact of professional development on teacher and student outcomes. University academic researchers are also keenly familiar and competent in research matters. They can hence effectively model quality research work to teachers. While university faculty has the methodological and theoretical knowledge, teachers have the practical knowledge to bring to the table. Furthermore, while the former benefit from gaining empirical evidence from the ground to generate new knowledge especially in empirically linking action research to teaching and student outcomes, the latter from gaining support in terms of methodological and theoretical knowledge. In this arrangement, the work of 'action' and 'research' are not contradictorily mixed but shared between two specialists - the university faculty member who provides the 'research' expertise, and the school teacher who provides the 'action' expertise. The partnership between university and schools can be built with varying configurations (e.g., Bruce, Flynn, \& Stagg-Peterson, 2011; Taylor et al., 2012), albeit being mindful of its potential difficulties (e.g., Bevins \& Price 2014; Noffke, 1997; Rosendahl \& Rönnerman, 2006; Somekh, 1994). In the Singapore education context, the work promoting action research between academics from the National Institute of Education (NIE), Nanyang Technological University and schools can be further strengthened. An example is the compilation of action research projects into a book by school teachers by an academic staff at NIE (Chew, 2006).

On the whole, the overarching purpose of strengthening leadership direction and professional development support for action research, and nurturing a positive teacher belief on action research by closing the links between action research and student 
outcomes is to hit the pragmatic sweet spot where teachers generally experience substantive and substantial benefits in doing action research without comprising their dayto-day professional lives.

\section{Author's information}

Salleh Hairon is Assistant Dean Doctor in Education with the Graduate Studies and Professional Learning Programme Office, and Assistant Professor with the Policy and Leadership Studies Academic Group, at the National Institute of Education, Nanyang Technological University, Singapore. His research interests include distributed leadership, teacher leadership, professional learning communities, action research and education reforms.

Ethics approval and consent to participate

As this manuscript is a review article, ethics approval and consent were not required.

\section{Competing interests}

The author declares that he has no competing interests.

\section{Publisher's Note}

Springer Nature remains neutral with regard to jurisdictional claims in published maps and institutional affiliations.

Received: 22 December 2016 Accepted: 22 September 2017

Published online: 04 October 2017

\section{References}

Apple, M. (1989). Teachers and texts. New York: Routledge \& Kegan Paul.

Bevins, S., \& Price, G. (2014). Collaboration between academics and teachers: A complex relationship. Educational Action Research, 22(2), 270-284

Borg, S. (2010). Language teacher research engagement. Language Teaching, 43(4), 391-429.

Bruce, C. D., Flynn, T., \& Stagg-Peterson, S. (2011). Examining what we mean by collaboration in collaborative action research: A cross-case analysis. Educational Action Research, 19(4), 433-452.

Capobianco, B., \& Feldman, A. (2002). Formative assessment action research: A study of teacher learning by using technology. Paper presented at the National Association for Research in Science Teaching International Conference. LA, April: New Orleans.

Capobianco, B., \& Feldman, A. (2006). Promoting quality for teacher action research: Lessons learned from science teachers' action research. Educational Action Research, 14(4), 497-512.

Carr, W., \& Kemmis, S. (1986). Becoming critical: Education, knowledge and action research. London: Falmer Press.

Chew, L. C. (2006). Action research across the curriculum. Singapore: Pearson.

Cochran-Smith, M., \& Lytle, S. (1999). Relationships of knowledge and practice: Teacher learning in communities. In P. Pearson \& A. Iran-Nejad (Eds.), Review of research in education, 24, (pp. 249-307). Washington, D.C American Educational Research Association.

Cochran-Smith, M., \& Lytle, S. L. (2009). Inquiry as stance: Practitioner research for the next generation. New York: Teachers College Press.

Cohen, J., Cook-Sather, A., Lesnick, A., Alter, Z., Awkward, R., Decius, F., et al. (2013). Students as leaders and learners: Towards self-authorship and social change on a college campus. Innovations in Education and Teaching International, 50(1), 3-13.

Darling-Hammond, L., Wei, R. C., Andree, A., Richardson, N., \& Orphanos, S. (2009). Professional learning in the learning profession: A status report on teacher development in the United States and abroad. Dallas, TX: National Staff Development Council Accessed on 23 Nov 2010. http://learningforward.org/docs/pdf/nsdcstudy2009.pdf.

Desimone, L. M. (2011). A primer on effective professional development. Kappan, 92(6), 68-71.

Elliott, J. (1991). Action research for educational change. Buckingham: Open University Press.

Elliott, J. (1998). The curriculum experiment: Meeting the challenge of social change. Buckingham: Open University Press

Ellis, N. (2014). Afraid to lose out: The impact of kiasuism on practitioner research in Singapore schools. Educational Action Research, 22(2), 235-250.

Feldman, A. (1996). Enhancing the practice of physics teachers: Mechanisms for the generation and sharing of knowledge and understanding in collaborative action research. Journal of Research in Science Teaching, 33(5), 513-540.

Feldman, A. (1999). The role of conversation in collaborative action research. Educational Action Research, 7(1), 125-144.

Feldman, A. (2002). Existential approaches to action research. Educational Action Research, 10(2), 233-252.

Freeman, D. (1998). Doing teacher research: From inquiry to understanding. Pacific Grove: Heinle \& Heinle.

Glanz, J. (2014). Action research: An educational leader's quide to school improvement (3rd ed.). Lanham, Maryland: Rowman \& Littlefield.

Groundwater-Smith, S., \& Mockler, N. (2005). Practitioner research in education, beyond celebration. Refereed paper presented to the Australian Association for Research in Education focus Conference. Australia, July: Cairns.

Guskey, T. R. (2002). Professional development and teacher change. Teachers and Teaching: Theory and Practice, 8(3/4), 381-391.

Habermas, J. (1971). Knowledge and the human interest. Boston: Beacon

Hairon, S. (2003). A qualitative study of Singapore primary school teachers' conceptions of educational change. Teaching and Learning, 24(2), 105-115.

Hairon, S. (2006). Action research In Singapore education - constraints and sustainability. Educational Action Research $14(4), 513-523$. 
Hairon, S. (2008). Teacher professional development in the TSLN era: Current challenges and future direction. In J. Tan \& P. T. Ng (Eds.), Thinking Schools, Learning Nation: Contemporary issues and challenges (pp. 87-103). Singapore: Prentice Hall.

Hairon, S., \& Dimmock, C. (2012). Singapore schools and professional learning communities: Teacher professional development and school leadership in an Asian hierarchical system. Educational Review, 64(4), 405-424.

Hammersley, M. (2004). Action research: A contradiction in terms? Oxford Review of Education, 30(2), 165-181.

Hargreaves, A. (2010). Presentism, individualism, and conservatism: The legacy of Dan Lortie's schoolteacher: A sociological study. Curriculum Inquiry, 40(1), 143-154.

Hofstede, G. (2001). Culture's consequences: Comparing values, behaviors, institutions, and organizations across nations (2nd ed.). Thousand Oaks, CA: Sage.

Kemmis, S., \& McTaggart, R. (1988). The action research reader (3rd ed.). Deakin University Press, Victoria, 1988

Kuntz, A. M., Presnall, M. M., Priola, M., Tilford, A., \& Ward, R. (2013). Creative pedagogies and collaboration: An action research project. Educational Action Research, 21(1), 42-58.

Liew, W. M. (2005). Teachers' professional lives in the age of educational reform. In J. Tan \& P. T. Ng (Eds.) Shaping Singapore future: Thinking Schools, Learning Nation (pp. 137-166). Singapore: Prentice Hall.

Lim, C., Lee, C., Saito, E., \& Haron, S. S. (2011). Taking stock of lesson study as a platform for teacher development in Singapore. Asia-Pacific Journal of Teacher Education, 39(4), 353-365.

Martinovic, D., Wiebe, N., Ratkovic, S., Willard-Holt, C., Spencer, T., \& Cantalini-Williams, M. (2012). 'Doing research was inspiring': Building a research community with teachers. Educational Action Research, 20(3), 385-406.

Mauzy, D. K., \& Milne, R. S. (2002). Singapore politics under the People's Action Party. London: Routledge.

McGee, A. (2008). Critical reflection of action research used for professional development in a Middle Eastern Gulf State. Educational Action Research, 16(2), 235-250.

McNiff, J. (2013). Action research: Principles and practice (3rd ed.). London and New York: Routledge.

Ministry of Education, Singapore. (2005). CLEAR: Celebrating learning through action research. Singapore: Ministry of Education.

Ministry of Education, Singapore. (2006). CLEAR: Celebrating learning through action research. Singapore: Ministry of Education.

Ministry of Education, Singapore. (2007). CLEAR: Celebrating learning through action research. Singapore: Ministry of Education.

Noffke, S. (1997). Professional, personal, and political dimensions of action research. Review of Research in Education, 22(1), 305-343.

Robinson, V. M. J. (1993). Current controversies in action research. Public Administration Quarterly, 17(3), 263-290.

Rosendahl, L. B., \& Rönnerman, K. (2006). Facilitating school improvement: the problematic relationship between researchers and practitioners. Journal of In-service Education, 32(4), 499-511.

Sagor, R. (2000). Guiding school improvement with action research. Alexandria, VA: ASCD.

Soh, K. C. (2006a). Promoting action research in Singapore schools. New Horizons in Education, 53, 8-21.

Soh, K. C. (2006b). Workshop on action research: A guide for teachers to become teacher-researcher. Singapore.

Soh, K. C. (2011). At the rear mirror and through the wind screen: Teachers becoming action researchers in Singapore schools. New Horizons in Education, 59(1), 12-24.

Somekh, B. (1994). Inhabiting each other's castles: Towards knowledge and mutual growth through collaboration. Educational Action Research, 2(3), 357-381.

Somekh, B., \& Zeichner, K. M. (2009). Action research for educational reform: Remodelling action research theories and practices in local contexts. Educational Action Research, 17(1), 5-21.

Stenhouse, L. (1975). An introduction to curriculum research and development. London: Heinemann.

Tan, W. K., Macdonald, D., \& Rossi, T. (2009). Educational action research in Singapore: to prove or improve? Asia Pacific Journal of Education, 29(3), 357-371.

Tan, Y. S. M., \& Nashon, S. M. (2013). Promoting teacher learning through learning study discourse: The case of science teachers in Singapore. Journal of Science Teacher Education, 24(5), 859-877.

Tang, N. (2000). Teachers' Network: a new approach in the professional development of teachers. ASCD Review 9(3), 48-55.

Taylor, A., Puchner, L. D., Powell, M. B., Harris, V., \& Marshall, R. (2012). Reconceiving with action research: Working within and across communities of practice in a university/community college collaborative venture. Educational Action Research, 20(3), 333-351.

Tharman, S. (2005). Speech by Mr Tharman Shanmugaratnam, Minister for Education, at the MOE Work Plan Seminar 2004, Ngee Ann Polytechnic Convention Centre, Thursday 22 September, 10.00 a.m. Available on 23 Sept 2005. http:// www.moe.gov.sg/media/speeches/2005/sp20050922.htm.

Tripp, D. (2004). Teachers' Network: A new approach to the professional development of teachers in Singapore. In C. Day \& J. Sachs (Eds.), International handbook on the continuing professional development of teachers (pp. 191-214). Maidenhead: Open University Press.

Worthington, R. (2003). Governance in Singapore. London: Routledge Curzon.

Zeichner, K. (2009). Teacher education and the struggle for social justice. London \& New York: Routledge. 